\title{
An electron localization function and catastrophe theory analysis on the molecular mechanism of gas-phase identity $S_{N} 2$ reactions
}

\author{
Victor Polo • Patricio Gonzalez-Navarrete • \\ Bernard Silvi · Juan Andres
}

Received: 7 December 2007 / Accepted: 8 February 2008 / Published online: 29 February 2008

(C) Springer-Verlag 2008

\begin{abstract}
A set of four reactions, $\mathrm{XCH}_{3}+\mathrm{X}^{-}(\mathrm{X}=\mathrm{F}, \mathrm{Cl}, \mathrm{Br})$ and $\mathrm{ClSiH}_{3}+\mathrm{Cl}^{-}$, is investigated by means of the joint use of the electron localization function (ELF) and catastrophe theory $(\mathrm{CT})$ analysis in order to obtain new insights into the bond breaking/forming processes for identity $\mathrm{S}_{\mathrm{N}} 2$ gas-phase reactions. Using DFT calculations at the OLYP/6-311++G(d,p) level, the effect of nucleophile ( $\mathrm{F}, \mathrm{Cl}$, and $\mathrm{Br}$ anions) and the role of reacting centers $(\mathrm{C}$ or $\mathrm{Si})$ on the reaction mechanisms are investigated. The charge-shift character of carbon-halogen bonds is studied by determination of the weights of the Lewis resonance structures. In all $\mathrm{S}_{\mathrm{N}} 2$ reactions at the carbon atom, there is a progressive reduction on the covalent character of the $\mathrm{C}-\mathrm{X}$ bond from the reactant complex $(0.41,0.57$, 0.58 for $\mathrm{F}, \mathrm{Cl}$, and $\mathrm{Br}$, respectively) until the bond-breaking process, occurring before the transition structure is reached. On the other hand, the $\mathrm{Si}-\mathrm{Cl}$ bond maintains its degree of covalent character $(0.51)$ from the isolated fragments to the formation of a stable transition complex, presenting two silicon-chlorine charge-shifted bonds. The analysis of the ELF topology along the reaction path reveals that all reactions proceed via the same turning points of fold-type but the order is inverted for reactions taking place at $\mathrm{C}$ or $\mathrm{Si}$ atoms.
\end{abstract}

Dedicated to Prof. Nino Russo on the occasion of his 60th birthday.

Contribution to the Nino Russo Special Issue.

V. Polo $\cdot$ P. Gonzalez-Navarrete $\cdot$ J. Andres $(\varangle)$

Departament de Quìmica Fìsica i Analìtica, Universitat Jaume I, Apartat 224, 12080 Castelló, Spain

e-mail: andres@qfa.uji.es

B. Silvi

Laboratoire de Chimie Théorique, Université Pierre et Marie Curie,

4 Place Jussieu, 75252 Paris Cedex, France

e-mail: silvi@lct.jussieu.fr
Keywords Electron localization function (ELF) . Catastrophe theory $\cdot$ DFT calculations $\cdot \mathrm{S}_{\mathrm{N}} 2$ reactions . Methyl transfer reactions

\section{Introduction}

A very important field of theoretical chemical research stands on the application of procedures for the interpretation of chemical reactivity. Kinetic simulations are becoming more and more widely used in modelling of chemical processes of practical interest. Of all the theoretical concepts that constitute the rational basis of modern molecular kinetics, the concept of molecular mechanism associated with the electronic structure change during a chemical rearrangement is one of the most general but at the same time one of the most vaguely defined. Because chemical bonds and the subsequent chemical bond breaking/forming processes are not observable quantities, in the sense of quantum mechanics, and is not directly measurable, they must be defined by convention. Generally, one has the choice between several procedures to be used; theoretical methods being developed range from those based on high-level quantum chemical studies of potential energy surfaces (PESs) and sophisticated theories of kinetics and dynamics to simpler and faster methods based on empirical correlations and analogies. However, the connection and redistribution of electron density along the reaction pathway with the enhancement or diminishing of chemical reactivity remain unclear.

The analysis of the electronic structure at the stationary points (reactants, products, possible intermediates and transition structures, TSs) obtained upon geometry optimizations on the PES constitutes a key application of modern computational chemistry. But, theoretical chemistry should not only give accurate data for the geometries, energies and other observables properties, but a very important part of quantum 
chemical research should also be to interpret the results in terms of quantitative concepts derived from first principle calculations. A promising theory to reach this goal, is Richard Bader's "Atoms in Molecules" (AIM) [1] in which all the chemical information is provided by the charge density distribution, an observable quantity. Moreover, the concept of bond path [2] should play a central role in the description of the evolution of the electronic structure along a reaction path. Bader and his co-workers [3] have made some important achievements in this direction, particularly from a methodological point of view introducing Thom's Catastrophe Theory [4] (CT) for the first time in quantum chemistry. However, the applicability of AIM to the study of reaction mechanisms rapidly appeared to be mostly limited to intramolecular processes because there is no topological change in the charge density gradient field when a diatom dissociates. Bader's methodology has been further revisited by Krokidis et al. [5] who used the electron localization function (ELF) of Becke and Edgecombe [6] instead of the charge density. This approach, the bonding evolution theory (BET) according to its authors has proven its efficiency in a wide range of reactions such as proton transfers [7], two state reaction between a transition metal cation and a small molecule [810], sigmatropic rearrangements [11], cyclizations [12-14], and ring opening reactions $[15,16]$. Nevertheless, as far as one is concerned by electronic reaction mechanisms (in other words electron density transfer along the reaction path), it is very important to recover a more traditional description of the bonding in terms of Lewis structures.

Gas-phase ion chemistry, and particularly the study of ionmolecule reactions, has significantly furthered our understanding of intrinsic reactivity and helped to unravel the mechanism of chemical reactions under solvent-free conditions $[17,18]$. The molecular mechanism associated with bimolecular nucleophilic substitution $\left(\mathrm{S}_{\mathrm{N}} 2\right)$ reactions can be considered one of the most studied chemical reactions [1947]. Both experimental and theoretical works, over the past decades, are driven primarily by its crucial role in many synthetic routes [48]. As a result, these types of chemical rearrangements have been the focus of many experimental and theoretical studies in the gas phase [29]. Explication of the general molecular mechanism for nucleophilic substitution at carbon atom will help increase the understanding of the nature of these, and many more, biochemical processes. This is best exemplified by gas-phase nucleophilic displacement $\left(S_{N} 2\right)$ reactions where a lively interplay between experiment and theory has contributed to the elucidation of the energetics, the potential energy surface, and the dynamics of these reactions $[49,50]$. Brauman's extensive study of gasphase $S_{N} 2$ reactions has confirmed the double-well potential energy [51].

The $\mathrm{XCH}_{3}+\mathrm{X}^{-}(\mathrm{X}=\mathrm{F}, \mathrm{Cl}, \mathrm{Br})$ identity $\mathrm{S}_{\mathrm{N}} 2$ reactions are a widely studied methyl transfer reaction involving a synchronous one-electron transfer and bond interchange in methyl halogen, with a halogen ion being both the attacking nucleophile and leaving group. Both the reactants and products channels are equivalent, making the reaction pathway isoenergetic. There is an attraction between an anion and a molecule in the gas phase and the initial portion of the potential energy surface must be stabilizing and leads to an ion/molecule complex. This ion-dipole complex is stable in the gas phase. From here, the bond making/forming process has an energy demand; a transition structure will appear on the surface, separating pair ion/molecule complexes (reactant and product complexes). This leads to a double-well surface on the PES which is characterized by a central barrier, provided by a trigonal bipyramidal transition state with two associated minima: the reactant and product ion complexes. This central barrier disappears when the carbon atom is substituted by silicon atom and the the reaction corresponds to barrierless process and the energy profile changes from a double to a single-well PES and the TS turns into a stable pentacoordinate intermediate with the nucleophile and leaving group occupying apical positions.

Here we seek to add basic mechanistic understanding how breaking/forming process takes place during chemical reaction through the use of new computational tools based on the joint use of the topological analysis of the electron localization function and catastrophe theory. Hence, the principal aim of this work was to find a quantum chemical probe for the electronic character of the identity $\mathrm{S}_{\mathrm{N}} 2$ nucleophilic substitution, new insights into the effect of nucleophile $(\mathrm{F}, \mathrm{Cl}$, and $\mathrm{Br}$ anions) as well as the change of mechanism experimented by replacing the $\mathrm{C}$ reaction center by $\mathrm{Si}$ atom.

The article is organized as follows. The mathematical model and computing details are described in Sect. 2 and 3, respectively, followed by the results and discussion section. The main conclusions arising from this work are summarized in the last section.

\section{The mathematical model}

The dynamical system [52] and catastrophe theory [4] applied to the ELF gradient vector field provide a convenient mathematical model to study chemical reactions from the chemical bonding evolution point of view. Originally, the ELF function has been designed to measure the Fermi hole curvature calculated at the Hartree-Fock level. Savin's interpretation in terms of local excess kinetic energy due to Pauli repulsion [53] gave support to the calculation of ELF from Kohn-Sham orbitals. ELF has been alternatively interpreted, in terms of localized orbitals [54] and recently as the nonadditive (inter orbital) Fisher information contained in the electron distribution [55]. Recently, a generalization of Dobson's interpretation has been achieved independently by Kohout et al. [56] 
and by Silvi [57] who introduced a more general localization function, namely the spin pair composition defined as:

$c_{\pi}(\mathbf{r})=\bar{N}(\mathbf{r})^{-8 / 3} \bar{N}_{/ /(\mathbf{r})}$

in which $\bar{N}(\mathbf{r})$ denotes the number of same spin pair within a sampling volume centred at $\mathbf{r}$ containing $\bar{N}(\mathbf{r})$ electrons, i.e.,

$$
\begin{aligned}
\bar{N}_{/ /}(\mathbf{r}) & =\iint_{v(\mathbf{r})}\left(\Pi^{\alpha \alpha}\left(\mathbf{r}_{1}, \mathbf{r}_{2}\right)+\Pi^{\beta \beta}\left(\mathbf{r}_{1}, \mathbf{r}_{2}\right)\right) d \mathbf{r}_{1} d \mathbf{r}_{2} \bar{N}(\mathbf{r}) \\
& =\int_{v(\mathbf{r})} \rho(\mathbf{r}) d \mathbf{r}
\end{aligned}
$$

where $\Pi^{\sigma \sigma}\left(\mathbf{r}_{1}, \mathbf{r}_{2}\right)$ and $\rho(\mathbf{r})$, respectively, denote the $\sigma \sigma$ pair function and the electron density distribution. This function locates the boundaries between localized opposite spin pair domains as shown in the example of Fig. 1. This figure represents a box of constant density containing one electron pair in each half space, the charge $q$ being the integration of the density. The spin pair composition $\mathrm{c}_{\pi}(r)$ function is calculated at different points presenting a maximum value at the center of the box. It has been shown that ELF is an excellent approximation of the spin pair composition [57] enabling its generalization to correlated wave functions [58]. In practice, the localization function adopts a lorentzian form $\eta(\mathbf{r})=\left(1+c_{\pi}^{2}(\mathbf{r})\right)^{-1}$ which confines its values in the $[1,0]$ interval.

The dynamical system theory is based on the analogy between a vector field of class $C^{1}$ bound on a manifold and a velocity field, i.e. in the present case:

$\nabla \eta(\mathbf{r})=\frac{\mathrm{d} \mathbf{r}}{\mathrm{d} t}$

Integrating $\mathrm{d} \boldsymbol{r} / \mathrm{d} t$ with respect to the fictitious time variable $t$ determines trajectories which start and end in the neighbourhood of points at which the gradient vanishes, the $\alpha$ and $\omega$ limits, respectively. Of particular importance are the critical points $P$ of coordinate $\mathbf{r}_{P}$ at which $\nabla \eta\left(\mathbf{r}_{P}\right)=0.0$ and which are characterized by their index $I_{P}$, i.e. the number of positive

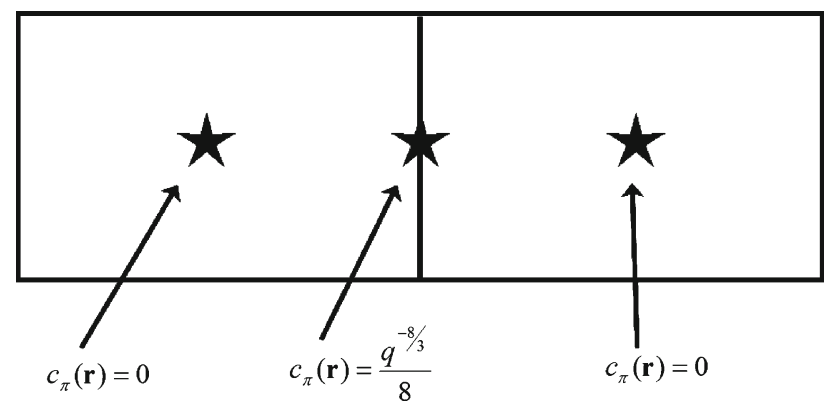

Fig. 1 Values of spin pair composition $c_{\pi}(r)$ function at different points. Each half space contains two opposite spin electrons and the density is assumed to be constant and integrates to the charge $q$ eigenvalues of the second derivative (hessian) matrix. A critical point is said hyperbolic when all the eigenvalues of the hessian matrix differ from zero. The set of points by which are built trajectories have a given critical point $P$ as $\omega$ limit is called the stable manifold of $P$. It is therefore possible to achieve the partition of the geometrical space occupied by a molecule into basins of attractors, in other words into stable manifolds of critical points of index 0 .

The topological partition of the ELF gradient field [59,60] yields basins of attractors which can be thought as corresponding to atomic cores, bonds and lone pairs. In a molecule one can find two types of basins. On the one hand are core basins surrounding nuclei with atomic number $Z>2$ and labelled $\mathrm{C}(\mathrm{A})$ where $\mathrm{A}$ is the atomic symbol of the element and on the other hand are the valence basins. The valence basins are characterized by the number of atomic valence shells to which they participate, or in other words by the number of core basins with which they share a boundary. This number is called the synaptic order [61]. Thus, there are monosynaptic, disynaptic, trisynaptic basins and so on. Monosynaptic basins, labelled V(A), correspond to the lone pairs of the Lewis model, and polysynaptic basins to the shared pairs of the Lewis model. In particular, disynaptic basins, labelled $\mathrm{V}(\mathrm{A}, \mathrm{X})$ correspond to two-centre bonds, trisynaptic basins, labelled $\mathrm{V}(\mathrm{A}, \mathrm{X}, \mathrm{Y})$ to three-centre bonds and so on. The valence shell of a molecule is the union of its valence basins. As hydrogen nuclei are located within the valence shell they are counted as a formal core in the synaptic order because hydrogen atoms have a valence shell. For example, the valence basin accounting for a $\mathrm{C}-\mathrm{H}$ bond is labelled $\mathrm{V}(\mathrm{C}, \mathrm{H})$ and called protonated disynaptic. The valence shell of an atom, say A, in a molecule is the union of the valence basins whose label lists contain the element symbol A. This description recovers Lewis's picture of the bonding [62] and provides very suggestive graphical representations of molecular systems. A quantitative analysis is further achieved by integrating the electron density and the pair functions over the volume of the basin yielding both basin populations and the corresponding covariance matrix [63] which measures the electron and supports a phenomenological interpretation in terms of weighted mesomeric structures [64].

The localization function depends upon a set of parameters such as the nuclear coordinates, the electronic state, the interaction with an external field, referred to as the control space. The topology depends therefore obviously on the value of the control space parameters. The changes are ruled by the Poincaré-Hopf theorem which state that:

$\sum_{P}(-1)^{I_{P}}=1$ 
introducing accordingly a very strong constraint due to the structure of the geometrical space. Along a reaction pathway which links the chemical structures and therefore the topologies of the ELF gradient fields of the reactants with those of the product the system experiences a series of structural stability domains (SSDs) within which all the critical points are hyperbolic separated by catastrophic points at which at least one critical point is non-hyperbolic. The bifurcation catastrophes occurring at these turning points are identified according to Thom's classification [4] which gives access to their unfolding, a compact polynomial expression which contains all the information about how ELF may change as the control parameters change. In this way, a chemical reaction is viewed as a sequence of elementary chemical processes characterized by a catastrophe. These chemical processes are classified according to the variation of the number of basins $\mu$ and/or of the synaptic order $\sigma$ of at least one basins. There are accordingly three types of chemical processes which correspond to $\Delta \mu<0, \Delta \mu>0$ and $\Delta \mu=0, \Delta \sigma \neq 0$.

Only three elementary catastrophes have been recognized so far in the chemical reactions: the fold, cusp and elliptic umbilic catastrophe. The fold catastrophe transforms a wandering point (i.e. a point which is not a critical one) into two critical points of different parity. Its unfolding is $x^{3}+u x$, where $x$ is the direction of the eigenvector corresponding to the eigenvalue of the Hessian matrix which changes of sign and $u$ is the control space parameters which governs the discontinuity. For $u<0$, the first derivative is positive for all $x$, the catastrophe takes place at $u=0$ for which both first and second derivatives are zero, and for $u>0$ there are two critical points at $x= \pm \sqrt{\frac{u}{3}}$. The cusp catastrophe transforms a critical point of a given parity into two critical points of the same parity and one of the opposite parity. Finally, the elliptic umbilic catastrophe changes the index of one critical point by 2 .

The sequence of catastrophes occurring along the reaction pathway is represented by the general formula

$\mathrm{N}_{1}-\mathrm{N}_{2}-F C S H E B P-\mathrm{N}_{3}$

introduced by Berski et al. [65]. In this system of notation $\mathrm{N}_{1}$ is the ordinal number of an analysed sequence which can be omitted when only one reaction is considered, i.e. $\mathrm{N}_{1}=1, \mathrm{~N}_{2}$ is the number of SSDs, "FCSHEBP" are the symbols of the catastrophes taken from their first letter in the original Thom's classification [4], i.e. $F=$ fold, $C=$ cusp, $S=$ swallow tail, $H=$ hyperbolic umbilic, $E=$ elliptic umbilic, $B=$ butterfly and $P=$ parabolic umbilic, and $\mathrm{N}_{3}$ indicates the end of the sequence. Catastrophes of the same type occurring simultaneously are indicated by $[A]_{n}$, where $n$ is the multiplicity of the catastrophe labelled by $A$. Moreover bold symbols are used to emphasize the first bond formation whereas the $\dagger$ superscript is used for those catastrophes which increase either the number of basins or the synaptic order, for example $C^{\dagger}$ corresponds to a cusp catastrophe in which an attractor gives rise to two new attractors and a saddle point of index 1. Finally, $\mathrm{N}_{3}$ indicates the end of the sequence.

\section{Computational details}

All quantum chemical calculations were carried out using the program GAUSSIAN 03 [66] the stationary points of the Born-Oppenheimer surface are calculated and characterized using the density functional theory based OLYP method $[67,68]$ together with the $6-311++G(d, p)$ basis set [69]. Recent benchmark calculations on $\mathrm{S}_{\mathrm{N}} 2$ model reactions have pointed out the suitability of the OLYP for accurate calculation of energy barriers [44]. Starting from the TS, the reaction path is traced following the intrinsic reaction coordinate (IRC) Rx in mass-weighted steps of $0.1 \mathrm{amu}^{1 / 2}$ bohr until the minimum is reached. For each point along the IRC path, the wavefunction is obtained and the ELF analysis is performed by means of the TOPMOD package [70] considering a cubical grid of stepsize smaller than 0.1. The ELF basins are visualized using the program Amira [71].

\section{Results and discussion}

ELF basins are analyzed as the reaction proceeds along the reaction pathways for rearrangements (1)-(4) and their topological changes will be classified in terms of turning points when a change of SSDs associated to ELF basis take place. Subscripts 1 and e are employed in order to distinguish the leaving $\left(\mathrm{X}_{1}\right)$ and entering $\left(\mathrm{X}_{\mathrm{e}}\right)$ halogens. Due to the compactness of the valence shell of halogen atoms $(\mathrm{X})$, the overall population of $\mathrm{V}_{i=1,2,3}(\mathrm{X})$ basins are taken into account instead of the internal reorganizations among lone pairs. Reaction (4) does not present a reactant complex, then, a reactant structure (RS) with a fixed $\mathrm{Si}-\mathrm{Cl}_{\mathrm{e}}$ interatomic distance of $3.5 \AA$ has been adopted for comparison purposes.
(1)

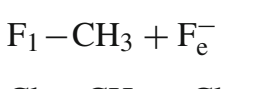
$\stackrel{\mathrm{TS}}{\rightleftharpoons}$
(2) $\mathrm{Cl}_{1}-\mathrm{CH}_{3}+\mathrm{Cl}_{\mathrm{e}}^{-}$ $\stackrel{\mathrm{TS} 2}{\rightleftharpoons}$
$\mathrm{F}^{-}+\mathrm{CH}_{3}-\mathrm{F}$
(3) $\mathrm{Br}_{1}-\mathrm{CH}_{3}+\mathrm{Br}_{\mathrm{e}}^{-}$
$\stackrel{\mathrm{TS} 3}{\rightleftharpoons}$
$\mathrm{Cl}^{-}+\mathrm{CH}_{3}-\mathrm{Cl}$
$\stackrel{\mathrm{TC} 4}{\rightleftharpoons}$
$\mathrm{Br}^{-}+\mathrm{CH}_{3}-\mathrm{Br}$
(4) $\mathrm{Cl}_{1}-\mathrm{SiH}_{3}+\mathrm{Cl}_{\mathrm{e}}^{-}$
$\stackrel{\mathrm{TC}}{\rightleftharpoons}$
$\mathrm{Cl}^{-}+\mathrm{SiH}_{3}-\mathrm{Cl}$

4.1 Determination of the Lewis resonance structures

The ELF basins of the isolated reactants or the reactive complex presents a charge-shift bond (CS) between carbon/ 


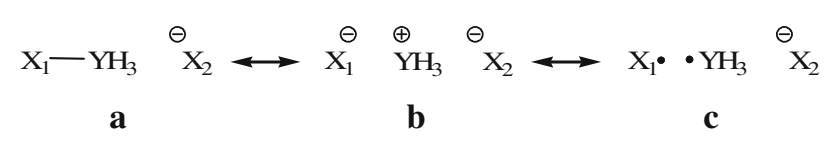

Scheme 1 Proposed Lewis resonance structures for reactant complexes (1)-(4)

silicon-halogen atoms as defined recently by Shaik et al. $[72,73]$ The main feature of this type of bond extracted from the ELF topology is the presence of a disynaptic basin with a population smaller than 2.00 electrons. The CS bond is explained as the superposition of (at least) two Lewis structures, covalent and ionic, yielding both valence-bond and ELF techniques similar results for the corresponding percentage of each the proposed structures. Following the ELF basins analysis we are able to estimate the weight of each configuration [74] (see supplementary information for the calculation details). Therefore, we can express the bonding pattern of the molecule as a superposition of several resonance forms. Hence, three resonance forms $(\mathbf{a}-\mathbf{c})$ are proposed for the reactant complexes (RC) (see Scheme 1) whereas four different forms $(\mathbf{d}-\mathbf{g})$ are considered for the transition structures (TSs) for reactions (1)-(3) and the transition/complex (TC) for reaction (4) as depicted in Scheme 2. Indeed, many other resonance forms can be proposed, however, for the sake of clarity we will constrain to $\mathbf{a}-\mathbf{g}$ which yields a reasonable description of the electronic pairing for all studied systems.

Structures a and $\mathbf{d}$ are the "covalent" forms, accounting for the sharing of two (a) or four (g) electrons between the substrate and the entering/leaving groups. Structures $\mathbf{b}$ and $\mathbf{e}$ represent the "ionic" forms, where both halogens present a negative charge while the $\mathrm{YH}_{3}$ group has a positive charge, establishing a triple ion pair. Structures $\mathbf{c}, \mathbf{f}-\mathbf{g}$ are the radical ones, where one of the halogens and the $\mathrm{YH}_{3}$ moiety accommodate one non-bonding electron on each. In this way, it is possible to determine the weighting coefficients of each resonance structure that yields an optimal fit to the calculated ELF basin populations (see supporting information for the calculation details).

Hence, at the RC there is a prevalence of the covalent structure (a) in all reactions: 0.41, 0.57, 0.58, and 0.51 for RCs (1)-(3) and RS-(4), respectively. There is also a significant contribution from the other two proposed mesomeric structures (see Table 1). Interestingly, the largest ionic character correspond to the molecule with the $\mathrm{Si}-\mathrm{Cl}_{1}$ bond (0.34), while for those molecules with $\mathrm{C}-\mathrm{F}_{1}, \mathrm{C}-\mathrm{Cl}_{1}$, and $\mathrm{C}-\mathrm{Br}_{1}$ bonds present weights of the ionic form (b) of 0.29, 0.19, and 0.17,
Table 1 Calculated weights of each mesomeric structure (a-g) for reactant complex (structure) and transition structure (or complex) of reactions (1)-(4)

\begin{tabular}{|c|c|c|c|c|c|c|c|c|}
\hline \multirow[t]{2}{*}{ Reaction } & \multirow[t]{2}{*}{$\mathrm{X}, \mathrm{Y}$} & \multicolumn{3}{|c|}{$\mathrm{RC} / \mathrm{RS}$} & \multicolumn{4}{|c|}{ TS/TC } \\
\hline & & a & $\mathrm{b}$ & $\mathrm{c}$ & $\mathrm{d}$ & e & $\mathrm{f}$ & g \\
\hline (1) & $\mathrm{F}, \mathrm{C}$ & 0.41 & 0.29 & 0.30 & 0.0 & 0.43 & 0.285 & 0.285 \\
\hline (2) & $\mathrm{Cl}, \mathrm{C}$ & 0.57 & 0.19 & 0.24 & 0.0 & 0.38 & 0.31 & 0.31 \\
\hline (3) & $\mathrm{Br}, \mathrm{C}$ & 0.58 & 0.17 & 0.25 & 0.0 & 0.33 & 0.335 & 0.335 \\
\hline (4) & $\mathrm{Cl}, \mathrm{Si}$ & 0.51 & 0.34 & 0.15 & 0.51 & 0.29 & 0.1 & 0.1 \\
\hline
\end{tabular}

respectively. These results can be correlated with those obtained using valence bond (VB) methodologies [75]. Structure b is equivalent to 3 and the weights can be directly compared. Hence, ELF basins yield lower weights than those obtained from BOVB calculations (in parenthesis) for the ionic structure 0.29 (0.462), 0.19 (0.267), $0.17(0.265)$ for $\mathrm{F}, \mathrm{Cl}$, and $\mathrm{Br}$, respectively. At the TS the weights of each structure change substantially, while for the $\mathrm{Y}=\mathrm{C}$ reactions (1)-(3), the weight of mesomeric structure $\mathbf{d}$ equals 0 due to the absence of disynaptic basins connecting $\mathrm{Y}-\mathrm{X}_{1, \mathrm{e}}$, for $\mathrm{Y}=\mathrm{Si}$, structure $\mathbf{d}$ has the largest weight $(0.51)$. It is also worth noting that in reaction (4) the weight of the covalent forms a at the RC and $\mathbf{d}$ at the TC are coincidentally equal. In reactions (1)-(3) an increase of the weights for the ionic forms from the RC (b) to the TS (e) can be observed. Again, the more electronegative halogen yields larger weight $\left(w_{\mathrm{e}}\right)$ values. Comparison with weights of valence bond structures obtained by BOVB calculations yields better results than the calculated for the RC. Hence, the values for the weights of the ionic structure $\mathbf{e}$ are slightly larger but in good agreement with those reported in Ref. [75]: 0.43 (0.507), 0.38 (0.541), 0.33 (0.403) for F, $\mathrm{Cl}$, and $\mathrm{Br}$, respectively.

\subsection{ELF and CT analysis of the reaction path}

The energy profiles along the reaction coordinate $(\mathrm{Rx})$ for reactions (1)-(4) are reported in Figs. 2, 3, 4 and 5 together to the SSDs representing the different ELF topologies along the reaction path. All reactions present three different SSDs (I-III) connected by two turning points of fold type. However, for reactions (1)-(3) the turning points correspond to the transformation of a disynaptic basin $\mathrm{V}\left(\mathrm{Y}-\mathrm{X}_{1}\right)$ into a monosynaptic basin $\mathrm{V}\left(\mathrm{X}_{1}\right)$ whereas the inverse process is observed in (4), the evolution of a monosynaptic basin into a disynaptic one. The fold turning point indicates a heterolytic bond breaking process, in contrast to the cusp turning point char-
Scheme 2 Proposed Lewis resonance structures for transition structures (1)-(4) or transition complex (4)

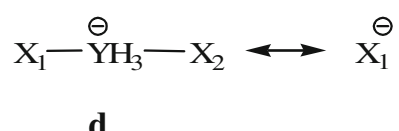

d

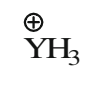

e
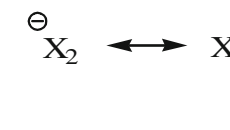

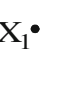

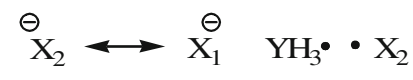

f g 


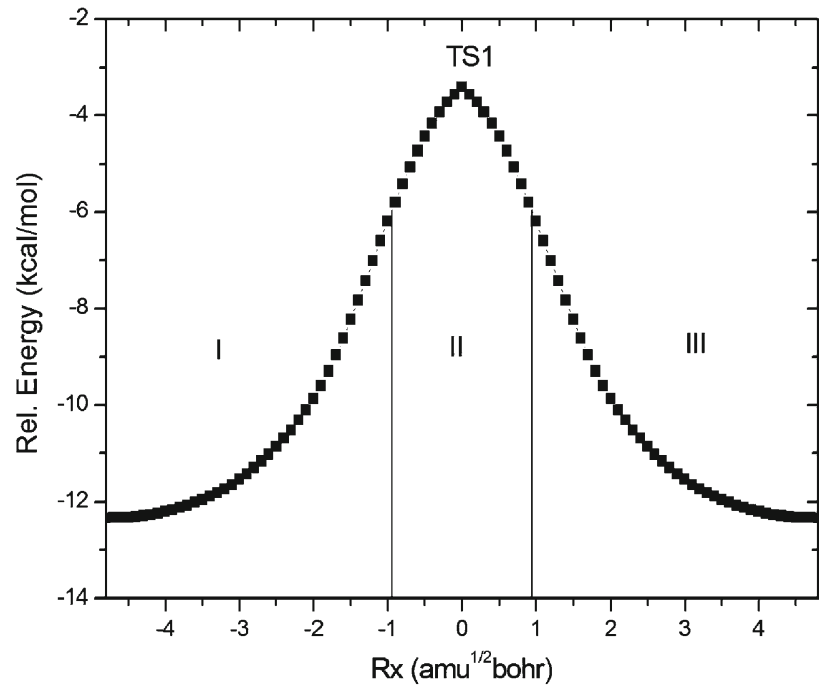

Fig. 2 OLYP/6-311++G(d,p) calculated energy profiles for the F$\mathrm{CH}_{3}+\mathrm{F}^{-}$reaction (1) (energy values relative to the isolated fragments)

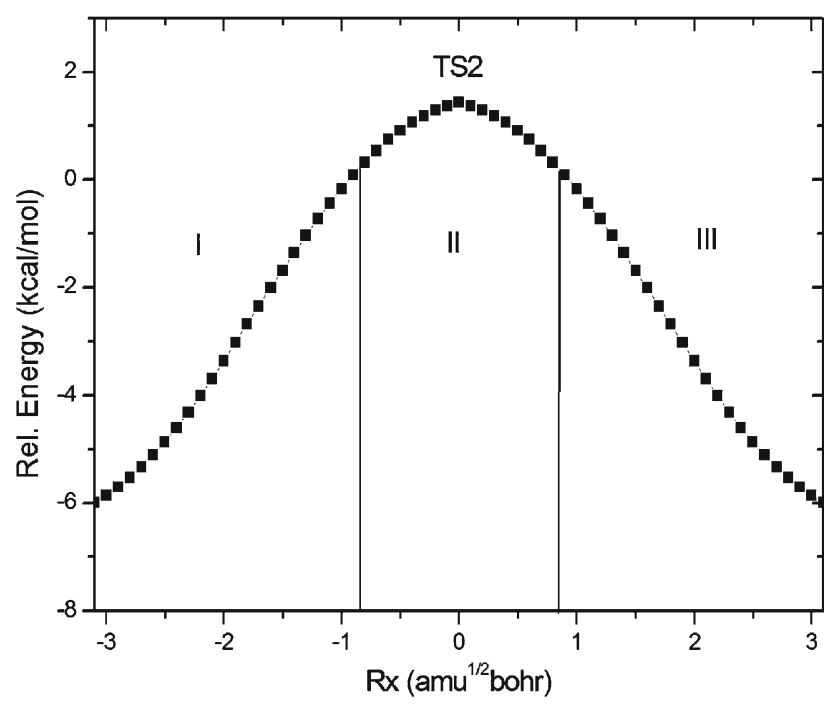

Fig. 3 OLYP/6-311++G(d,p) calculated energy profiles for the $\mathrm{Cl}-$ $\mathrm{CH}_{3}+\mathrm{Cl}^{-}$reaction (2) (energy values relative to the isolated fragments)

acteristic of homolytic bond breaking. Interestingly, reaction (4) presents the same turning points but the order is also exchange yielding three SSDs but of different ELF topology. Hence, in all three halogen-carbon $\mathrm{S}_{\mathrm{N}} 2$ reaction mechanisms studied in this work the $\mathrm{C}-\mathrm{X}$ bond is totally broken before reaching the transition structure, while in the reaction (4) the new chlorine-silicon bond is formed before the transition_complex. See Fig. 6 for a representation of the ELF basins for the reaction complexes (belonging to SSD-I) and the transition structures/complex (belonging to SSD-II). Using notation previously defined by Berski et al. [65] reactions (1)-(3) can be characterized as $3-F \boldsymbol{F}^{\dagger}-0$, while reaction (4) is given by $3-\boldsymbol{F}^{\dagger} F-0$.

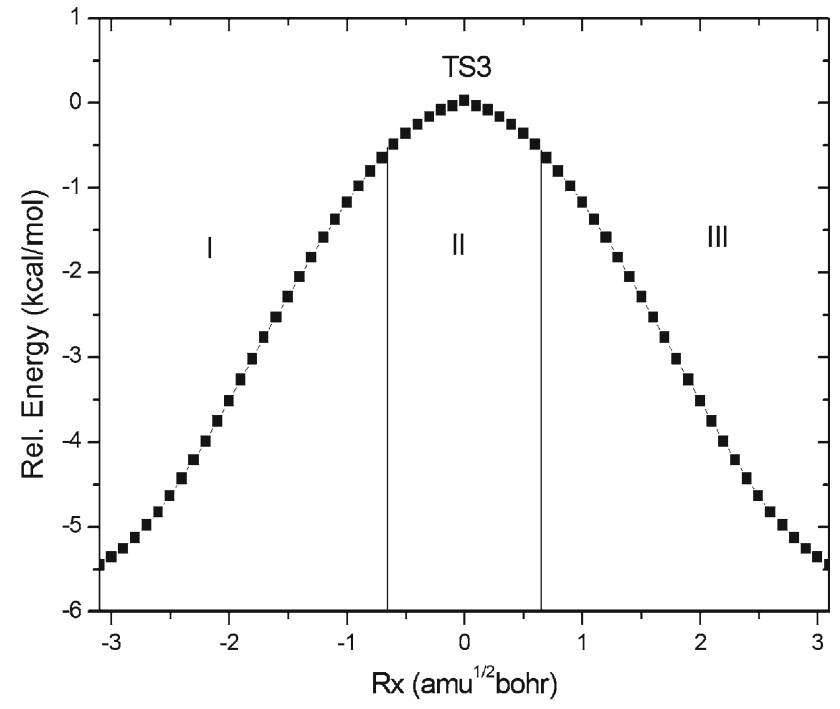

Fig. 4 OLYP/6-311++G(d,p) calculated energy profiles for the $\mathrm{Br}-$ $\mathrm{CH}_{3}+\mathrm{Br}^{-}$reaction (3) (energy values relative to the isolated fragments)

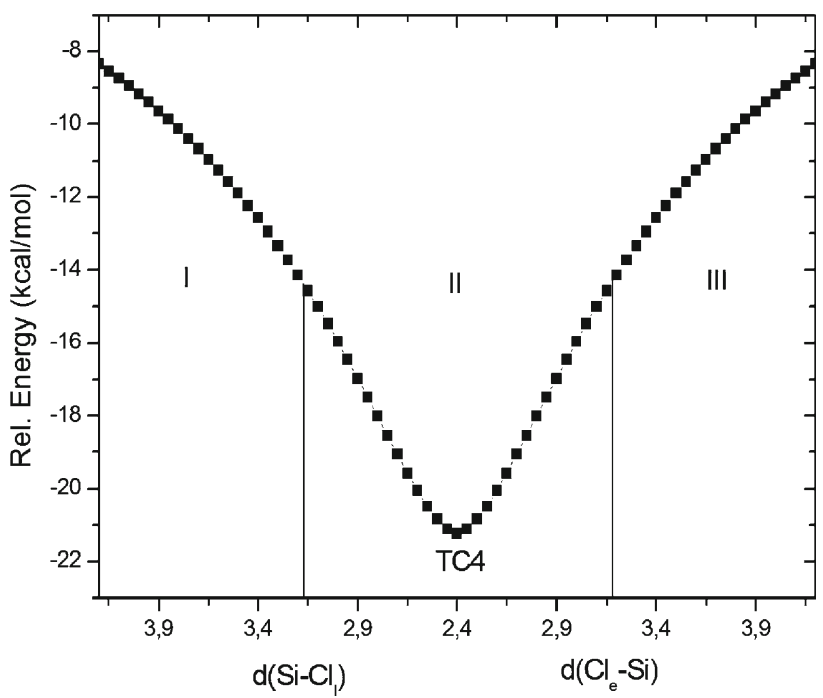

Fig. 5 OLYP/6-311++G(d,p) calculated energy profiles for the $\mathrm{Cl}-$ $\mathrm{SiH}_{3}+\mathrm{Cl}^{-}$reaction (4) (energy values relative to the isolated fragments)

The first SSD presents the same ELF topology as for the two isolated reactants. The formation of the reactive complex carries out a very small charge transfer from the anion to the substrate and a moderate increment in the ionic character of the halogen-carbon/silicon bond, as it can be observed by the smaller population of the corresponding disynaptic basin (see Tables 2, 3, 4, 5), without modification of the ELF topology. The integration of the electronic charge over the ELF basins along the reaction path reveals three behaviours: (1) a progressive increment in the electronic charge of the lone pairs of the leaving atom, (2) a noticeable charge transfer from the incoming atom and (3) a very small increment of 
(a)

$\mathrm{RC}$

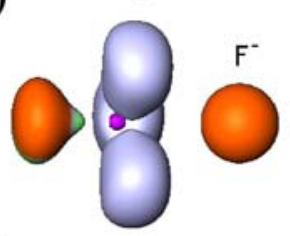

(b)

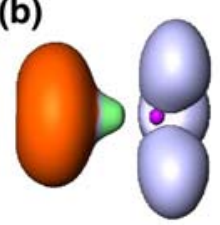

(c)
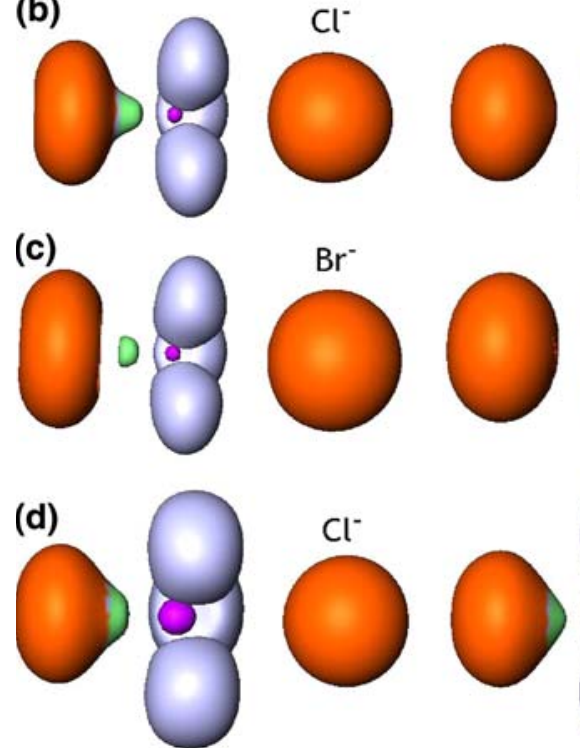

TS/TC
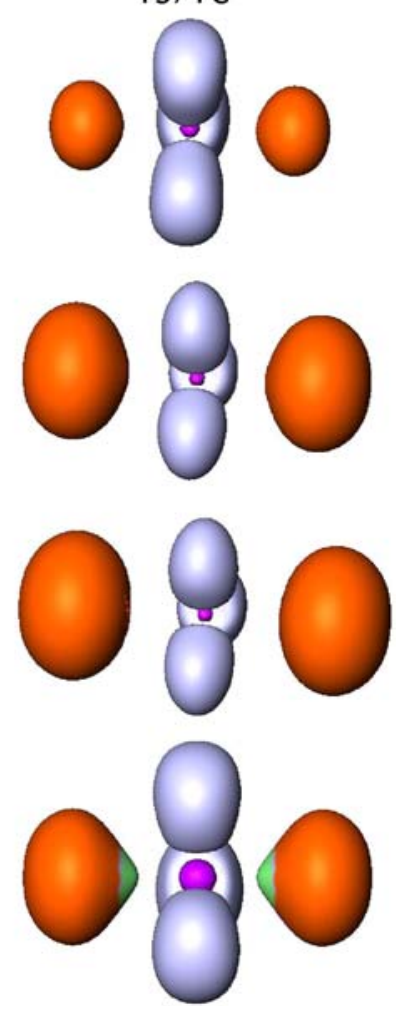

Fig. 6 Snapshots of ELF localization domains $(\eta=0.75)$ for reactant complexes (RC) and transition structures/complex (TS/TC) of reactions (1)-(4). purple for core, orange for monosynaptic and green for disynaptic

Table $2 \mathrm{Rx}$ (in $\mathrm{amu}^{1 / 2}$ bohr), relative energy (in $\mathrm{kcal} / \mathrm{mol}$ ), $\mathrm{rC}-\mathrm{F}_{1}$ and $\mathrm{rC}-\mathrm{F}_{\mathrm{e}}$ distances (in $\AA$ ), and integrated ELF basin populations for isolated fragments, and the initial and final points of each SSD for reaction (1)

\begin{tabular}{llllll}
\hline & & SSD-I & \multicolumn{3}{c}{ SSD-II } \\
\hline $\mathrm{Rx}$ & Fragments & $\mathrm{RC} 1$ & -1.0 & -0.9 & 0 (TS1) \\
$E_{\text {rel }}$ & 0.0 & -12.34 & -6.19 & -5.80 & -3.30 \\
$\mathrm{rC}-\mathrm{F}_{\mathrm{l}}$ & 1.398 & 1.452 & 1.658 & 1.675 & 1.877 \\
$\mathrm{rC}-\mathrm{F}_{\mathrm{e}}$ & - & 2.732 & 2.096 & 2.078 & 1.877 \\
$\mathrm{~V}\left(\mathrm{C}, \mathrm{F}_{1}\right)$ & 0.87 & 0.83 & 0.40 & - & - \\
$\mathrm{V}\left(\mathrm{F}_{1}\right)$ & 6.73 & 6.88 & 7.25 & 7.64 & 7.59 \\
$\mathrm{~V}\left(\mathrm{~F}_{\mathrm{e}}\right)$ & 7.98 & 7.86 & 7.71 & 7.73 & 7.59 \\
$\mathrm{~V}_{1,2,3}(\mathrm{H}, \mathrm{C})$ & 2.06 & 2.08 & 2.11 & 2.13 & 2.16 \\
\hline
\end{tabular}

the population of the hydrogenated basins. This increment in the population of the $\mathrm{V}(\mathrm{C}, \mathrm{H})$ basin can be traced back to the change of hybridization from a $\mathrm{sp}^{3}$ to a $\mathrm{sp}^{2}$ orbital of the $\mathrm{C}-\mathrm{H}$ bonds occurring from the reactants to the TS/TC using concepts based on the molecular orbital theory.

The turning points, connecting SSD-I and SSD-II , associated with the breaking of carbon-halogen bond of reactions (1)-(3), take place at $\mathrm{Rx}$ values of $1.0,-0.9$, and $-0.7 \mathrm{amu}^{1 / 2}$
Table $3 \mathrm{Rx}$ (in $\mathrm{amu}^{1 / 2}$ bohr), relative energy (in $\mathrm{kcal} / \mathrm{mol}$ ), $\mathrm{rC}-\mathrm{Cl}_{l}$ and $\mathrm{rC}-\mathrm{Cl}_{\mathrm{e}}$ distances (in $\AA$ ), and integrated ELF basin populations for isolated fragments, and the initial and final points of each SSD for reaction (2)

\begin{tabular}{llllll}
\hline & & SSD-I & \multicolumn{3}{c}{ SSD-II } \\
\hline $\mathrm{Rx}$ & Fragments & $\mathrm{RC} 2$ & -0.9 & -0.8 & 0 (TS2) \\
$E_{\mathrm{rel}}$ & 0.0 & -7.96 & 0.09 & 0.33 & 1.44 \\
$\mathrm{rC}-\mathrm{Cl}_{1}$ & 1.796 & 1.838 & 2.201 & 2.217 & 2.371 \\
$\mathrm{rC}-\mathrm{Cl}_{\mathrm{e}}$ & - & 3.432 & 2.540 & 2.524 & 2.371 \\
$\mathrm{~V}\left(\mathrm{C}, \mathrm{Cl}_{1}\right)$ & 1.25 & 1.16 & 0.44 & - & - \\
$\mathrm{V}\left(\mathrm{Cl}_{1}\right)$ & 6.65 & 6.54 & 7.15 & 7.54 & 7.44 \\
$\mathrm{~V}\left(\mathrm{Cl}_{\mathrm{e}}\right)$ & 8.00 & 7.88 & 7.73 & 7.89 & 7.44 \\
$\mathrm{~V}_{1,2,3}(\mathrm{H}, \mathrm{C})$ & 2.05 & 2.07 & 2.15 & 2.15 & 2.18 \\
\hline
\end{tabular}

Table $4 \mathrm{Rx}$ (in $\mathrm{amu}^{1 / 2} \mathrm{bohr}$ ), relative energy (in $\mathrm{kcal} / \mathrm{mol}$ ), $\mathrm{rC}-\mathrm{Cl}_{l}$ and $\mathrm{rC}-\mathrm{Cl}_{\mathrm{e}}$ distances (in $\AA$ ), and Integrated ELF basin populations for isolated fragments, and the initial and final points of each SSD for reaction (3)

\begin{tabular}{llllll}
\hline & \multicolumn{3}{l}{ SSD-I } & \multicolumn{3}{l}{ SSD-II } \\
\hline $\mathrm{Rx}$ & Fragments & $\begin{array}{l}\text { Reaction } \\
\text { complex }\end{array}$ & -0.7 & -0.6 & 0 (TS3) \\
& & -7.33 & -0.64 & -0.49 & 0.03 \\
$E_{\text {rel }}$ & 0.0 & 2.004 & 2.393 & 2.409 & 2.522 \\
$\mathrm{rC}-\mathrm{Br}_{1}$ & 1.957 & 3.567 & 2.652 & 2.636 & 2.522 \\
$\mathrm{rC}-\mathrm{Br}_{\mathrm{e}}$ & - & 1.11 & 0.24 & - & - \\
$\mathrm{V}\left(\mathrm{C}, \mathrm{Br}_{1}\right)$ & 1.25 & 6.89 & 7.58 & 7.83 & 7.80 \\
$\mathrm{~V}\left(\mathrm{Br}_{1}\right)$ & 6.75 & 8.15 & 7.98 & 7.98 & 7.80 \\
$\mathrm{~V}\left(\mathrm{Br}_{\mathrm{e}}\right)$ & - & 2.06 & 2.18 & 2.17 & 2.2 \\
$\mathrm{~V}_{1,2,3}(\mathrm{H}, \mathrm{C})$ & 2.04 & & & & \\
\hline
\end{tabular}

Table 5 Relative energy (in $\mathrm{kcal} / \mathrm{mol}$ ), $\mathrm{rSi}-\mathrm{Cl}_{\mathrm{l}}$ and $\mathrm{rSi}-\mathrm{Cl}_{\mathrm{e}}$ distances (in $\AA$ ), and Integrated ELF basin populations for isolated fragments, and the initial and final points of each SSD for reaction (4)

\begin{tabular}{lccccc}
\hline & \multicolumn{3}{c}{ SSD-I } & \multicolumn{3}{c}{ SSD-II } \\
\hline$E_{\text {rel }}$ & 0.0 & -12.52 & -14.57 & -15.02 & -21.24 \\
$\mathrm{rSi}-\mathrm{Cl}_{l}$ & 2.082 & 2.194 & 2.228 & 2.236 & 2.383 (TC4) \\
$\mathrm{rSi}-\mathrm{Cl}_{\mathrm{e}}$ & - & 3.5 & 2.950 & 2.900 & 2.383 \\
$\mathrm{~V}\left(\mathrm{Si}_{1}, \mathrm{Cl}_{1}\right)$ & 1.47 & 1.33 & 0.83 & 0.88 & 1.03 \\
$\mathrm{~V}\left(\mathrm{Cl}_{1}\right)$ & 6.56 & 6.89 & 7.04 & 7.02 & 6.80 \\
$\mathrm{~V}\left(\mathrm{Si}_{1} \mathrm{Cl}_{\mathrm{e}}\right)$ & - & - & 0.48 & 0.42 & 1.03 \\
$\mathrm{~V}\left(\mathrm{Cl}_{\mathrm{e}}\right)$ & - & 7.61 & 7.35 & 7.41 & 6.80 \\
$\mathrm{~V}_{1,2,3}(\mathrm{H}, \mathrm{Si})$ & 2.04 & 2.05 & 2.07 & 2.07 & 2.05 \\
\hline
\end{tabular}

bohr, for $\mathrm{F}, \mathrm{Cl}$ and $\mathrm{Br}$, respectively. These points correspond to $\mathrm{C}-\mathrm{X}_{1}$ bond distances of $1.658,2.201$, and $2.393 \AA$, for $\mathrm{F}, \mathrm{Cl}$ and $\mathrm{Br}$, respectively. Consequently, no forming/breaking bonds processes take place in the vicinities of the TS. This result is in agreement with recent works pointing out the predominance of the steric over orbital effects at the TS using the framework provided by the energy decomposition 
analysis method [76]. However, it should be remarked that our ELF analysis does not support a pentacovalently bonded carbon atom at the TSs for reactions (1)-(3) as indicated by the absence of a disynaptic basin connecting carbon to the entering/leaving moieties. Although carbon and silicon present the same valence structure, the arrangement of electron pairs for TS2 and the TC4 reactions are substantially different. Silicon atom can afford a pentacoordinate structure as demonstrated by the existence of five ELF basins sharing a common boundary with the core basin of silicon (see Fig. 6).

\section{Conclusions}

A theoretical study based on both topological analysis of the ELF and CT have been carried out to disentangle the forming/breaking bond processes and electronic rearrangements along the reaction path associated with the molecular mechanism for the gas-phase identity $\mathrm{XCH}_{3}+\mathrm{X}^{-}(\mathrm{X}=\mathrm{F}, \mathrm{Cl}, \mathrm{Br})$ and $\mathrm{ClSiH}_{3}+\mathrm{Cl}^{-}$reactions. Carbon/silicon-halogen bonds can be considered as a paradigmatic example of charge-shifted bonds. The weights of the Lewis resonance structures for the reactants complexes and transition structures/complex have been calculated from ELF basin populations obtaining an excellent agreement with those calculated using high-level valence bond methods. The analysis of the ELF topology along the reaction path reveals that all reactions proceed via the same turning points of fold-type but the order is inverted for reactions taking place at $\mathrm{C}$ or $\mathrm{Si}$ atoms. In all $\mathrm{S}_{\mathrm{N}} 2$ reactions at the carbon atom, the transition structures are characterized by ionic species without the presence of disynaptic basin connecting the halogens and the carbon atom. For the reaction at the silicon atom, the process formation of the new $\mathrm{Si}-\mathrm{Cl}_{\mathrm{e}}$ bond takes place before the $\mathrm{Si}-\mathrm{Cl}_{1}$ bond is broken, leading to a pentacoordinate silicon atom at the $\mathrm{TC}$ in the single-well potential energy surface.

Acknowledgments This work was supported by the Ministerio de Educación y Ciencia (MEC) project CTQ2006-15447-C02-01, Generalitat Valenciana (GV), Projects ACOMP06/122 and GV2007/106. V. P. and P. G.-N. thank to support by the JdC program and doctoral FPI fellowship from the MEC, respectively. The authors are also grateful to the Servei d'Informatica, Universitat Jaume I for generous allotment of computer time.

\section{References}

1. Bader RFW (1990) Atoms in molecules. A quantum theory. Oxford University Press, Oxford

2. Bader RFW (1998) J Phys Chem A 102:7314

3. Tal Y, Bader RFW, Nguyendang TT, Ojha M, Anderson SG (1981) J Chem Phys 74:5162

4. Thom R (1975) Structural stability and morphogenesis: an outline of a general theory of models. Benjamin, Reading

5. Krokidis X, Noury S, Silvi B (1997) J Phys Chem A 101:7277
6. Becke AD, Edgecombe KE (1990) J Chem Phys 92:5397

7. Krokidis X, Goncalves V, Savin A (1998) J Phys Chem A 102:5065

8. Michelini MD, Sicilia E, Russo N, Alikhani ME, Silvi B (2003) J Phys Chem A 107:4862

9. Michelini MD, Russo N, Alikhani ME, Silvi B (2004) J Comput Chem 25:1647

10. Michelini MD, Russo N, Alikhani ME, Silvi B (2005) J Comput Chem 26:1284

11. Polo V, Andres J (2005) J Comput Chem 26:1427

12. Polo V, Andres J, Castillo R, Berski S, Silvi B (2004) Chem-Eur J 10:5165

13. Santos JC, Polo V, Andres J (2005) Chem Phys Lett 406:393

14. Santos JC, Andres J, Aizman A, Fuentealba P, Polo V (2005) J Phys Chem A 109:3687

15. Polo V, Domingo LR, Andres J (2006) J Org Chem 71:754

16. Polo V, Andres J (2007) J Chem Theory Comput 3:816

17. DePuy CH (2000) Int J Mass spectrom 200:79

18. Gronert S (2001) Chem Rev 101:329

19. Tucker SC, Truhlar DG (1990) J Am Chem Soc 112:3338

20. Shaik S, Schlegel HB, Wolfe S (1992) Theoretical aspects of physical organic chemistry. The SN2 mechanism. Wiley, New York

21. Hu WP, Truhlar DG (1994) J Am Chem Soc 116:7797

22. Harder S, Streitwieser A, Petty JT, Schleyer PV (1995) J Am Chem Soc 117:3253

23. Streitwieser A, Choy GSC, AbuHasanayn F (1997) J Am Chem Soc 119:5013

24. Cossi M, Adamo C, Barone V (1998) Chem Phys Lett 297:1

25. Su T, Wang HB, Hase WL (1998) J Phys Chem A 102:9819

26. Schmatz S, Clary DC (1999) J Chem Phys 110:9483

27. Borisov YA, Arcia EE, Mielke SL, Garrett BC, Dunning TH (2001) J Phys Chem A 105:7724

28. Pagliai M, Raugei S, Cardini G, Schettino V (2001) Phys Chem Chem Phys 3:2559

29. Laerdahl JK, Uggerud E (2002) Int J Mass Spectrom 214:277

30. Kormos BL, Cramer CJ (2003) J Org Chem 68:6375

31. Mo SJ, Vreven T, Mennucci B, Morokuma K, Tomasi J (2004) Theor Chem Acc 111:154

32. Vayner G, Houk KN, Jorgensen WL, Brauman JI (2004) J Am Chem Soc 126:9054

33. Adamovic I, Gordon MS (2005) J Phys Chem A 109:1629

34. Almerindo GI, Pliego JR (2005) Org Lett 7:1821

35. Bento AP, Sola M, Bickelhaupt FM (2005) J Comput Chem 26:1497

36. Halls MD, Raghavachari K (2005) Nano Lett 5:1861

37. Hasanayn F, Streitwieser A, Al-Rifai R (2005) J Am Chem Soc 127:2249

38. Pliego JR (2005) J Mol Catal A Chem 239:228

39. Tondo DW, Pliego JR (2005) J Phys Chem A 109:507

40. Fernandez-Ramos A, Miller JA, Klippenstein SJ, Truhlar DG (2006) Chem Rev 106:4518

41. Pliego JR (2006) Org Biomol Chem 4:1667

42. Uggerud E (2006) Chem-Eur J 12:1127

43. Pliego JR, Pilo-Veloso D (2007) J Phys Chem B 111:1752

44. Swart M, Sola M, Bickelhaupt FM (2007) J Comput Chem 28:1551

45. Zheng JJ, Zhao Y, Truhlar DG (2007) J Chem Theory Comput 3:569

46. Gonzales JM, Pak C, Cox RS, Allen WD, Schaefer HF, Csaszar AG, Tarczay G (2003) Chem-Eur J 9:2173

47. Glukhovtsev MN, Pross A, Schlegel HB, Bach RD, Radom L (1996) J Am Chem Soc 118:11258

48. March J (1992) Advanced organic chemistry. Wiley, New York

49. Chabinyc ML, Craig SL, Regan CK, Brauman JI (1998) Science 279:1882

50. Hase WL (1994) Science 266: 998-1002 
51. Brauman JI, Olmstead CAL WN (1974). J Am Chem Soc 96:4030

52. Abraham RH, Shaw CD (1992) Dynamics: the geometry of behavior, 2nd edn. Addison-Wesley, Redwood City

53. Savin A, Jepsen O, Flad J, Andersen OK, Preuss H, Vonschnering HG (1992) Angew Chem Int Ed Engl 31:187

54. Burdett JK, McCormick TA (1998) J Phys Chem A 102:6366

55. Nalewajski RF, Koster AM, Escalante S (2005) J Phys Chem A 109:10038

56. Kohout M, Wagner ER, Grin Y (2006) Int J Quantum Chem 106:1499

57. Silvi B (2003) J Phys Chem A 107: 3081-3085

58. Matito E, Silvi B, Duran M, Sola M (2006) J Chem Phys 125:024301

59. Silvi B, Savin A (1994) Nature 371:683

60. Haussermann U, Wengert S, Hofmann P, Savin A, Jepsen O, Nesper R (1994) Angew Chem Int Ed Engl 33:2069

61. Silvi B (2002) J Mol Struct 614:3

62. Lewis GN (1916) J Am Chem Soc 38:762

63. Silvi B (2004) Phys Chem Chem Phys 6:256

64. Poater J, Duran M, Sola M, Silvi B (2005) Chem Rev 105: 39113947

65. Berski S, Andres J, Silvi B, Domingo LR (2006) J Phys Chem A 110: 13939-13947

66. Frisch MJ, Trucks GW, Schlegel HB, Scuseria GE, Robb MA, Cheeseman JR, Montgomery Jr. JA, Vreven T, Kudin KN, Burant JC, Millam JM, Iyengar SS, Tomasi J, Barone V, Mennucci B,
Cossi M, Scalmani G, Rega N, Petersson GA, Nakatsuji H, Hada M, Ehara M, Toyota K, Fukuda R, Hasegawa J, Ishida M, Nakajima T, Honda Y, Kitao O, Nakai H, Klene M, Li X, Knox JE, Hratchian HP, Cross JB, Bakken V, Adamo C, Jaramillo J, Gomperts R, Stratmann RE, Yazyev O, Austin AJ, Cammi R, Pomelli C, Ochterski JW, Ayala PY, Morokuma K, Voth GA, Salvador P, Dannenberg JJ, Zakrzewski VG, Dapprich S, Daniels AD, Strain MC, Farkas O, Malick DK, Rabuck AD, Raghavachari K, Foresman JB, Ortiz JV, Cui Q, Baboul AG, Clifford S, Cioslowski J, Stefanov BB, Liu G, Liashenko A, Piskorz P, Komaromi I, Martin RL, Fox DJ, Keith T, Al-Laham MA, Peng CY, Nanayakkara A, Challacombe M, Gill PMW, Johnson B, Chen W, Wong MW, Gonzalez C, and Pople JA (2004) Gaussian 03, Revision C.02. Gaussian, Wallingford

67. Handy NC, Cohen A (2001) Mol Phys 99:403

68. Lee CT, Yang WT, Parr RG (1988) Phys Rev B 37:785

69. Harihara PC, Pople JA (1973) Theor Chim Acta 28:213

70. Noury S, Krokidis X, Fuster F, Silvi B (1999) Comput Chem 23:597

71. Amira 3.0, (2003) . Concepts I-V, Berlin

72. Shaik S, Danovich D, Silvi B, Lauvergnat DL, Hiberty PC (2005) Chem-Eur J 11:6358

73. Hiberty PC, Megret C, Song LC, Wu W, Shaik S (2006) J Am Chem Soc 128:2836

74. Polo V, Andres J, Silvi B (2007) J Comput Chem 28:857

75. Song LC, Wu W, Hiberty PC, Shaik S (2006) Chem-Eur J 12:7458

76. Bento AP, Bickelhaupt FM (2007) J Org Chem 72:2201 